\section{Source of Pollen, Distance from Pollinizer, and Time of Pollination Affect Yields in Block-type Pecan Orchards}

\author{
Bruce W. Wood \\ U.S. Department of Agriculture, Agricultural Research Station, Southeastern \\ Fruit and Tree Nut Research Laboratory, Byron, GA 31008
}

Additional index words. flowering, production, orchard management, temperature, age, Carya illinoinensis

\begin{abstract}
Inadequate cross-pollination of pecan [Carya illinoinensis (Wangenh.) K. Koch] occurred in block-type orchards generally thought exempt from pollination-related crop losses because of an abundance of nearby potential pollinizers. "Off-genotypes" appeared to be potentially major assets in such orchards due to their role as backup pollinizers; hence, their presence insures against crop losses due to poor pollination. Fruit-set in 'Desirable' main crop rows declined sigmoidally as distance from 'Stuart' pollinizer rows increased. For 15.4-m row spacings, rate of decrease was maximum between 49 and $78 \mathrm{~m}$, depending on crop year. Maximum fruit-set was in rows immediately adjacent to the pollinizer. Tree age/size and spring temperature influences on the characteristics of flower maturity windows are probably primary factors contributing to pollination-related fruitset losses in block-type orchards relying upon pollen from a single complementary pollinizer or from neighborhood trees. For example, flower maturity was earlier in older/ larger trees, and higher spring temperatures accelerated catkin development relative to that of pistillate flowers. Maximum fruit-set occurred when pistillate flowers received pollen around 1 day or less after becoming receptive, whereas no fruit-set occurred when they were pollinated around four or more days after initial receptivity. These findings indicate that many block-type orchards in the southeastern United States are exhibiting pollination-related crop reductions and that future establishment of such orchards merits caution regarding the spatial and temporal distribution of pollinizers.
\end{abstract}

Pecan is a wind-pollinated monoecious crop that exhibits heterodichogamy (Adriance, 1930; Grauke and Thompson, 1996). Synchrony of pollen release and of pistillate flower receptivity varies from none to complete and is influenced by genotype and environmental conditions (Wood et al., 1997; Worley et al., 1992). Pollination dynamics can therefore cause fruit-set problems. Crop losses can be due to poor pollination, excessive self-pollination, or xenia (Romberg and Smith, 1946). Environmental and age factors potentially influence crop loads in certain tree fruit crops (Buban, 1996) and may do so in pecan.

The general dearth of pollinizers in the vicinity of southwestern U.S. orchards led to research establishing that pollination-related croplosses occur in that region when pollinizer distance is two or more rows from the main crop cultivar (Marquard, 1988). Conversely, the relative abundance of diverse cultivars and feral germplasm proximate to most orchards in the region has contributed to the commonly accepted belief that pollination is not a problem. This has been partially based on observations of the great abundance (Woodroof, 1924, 1930) and mobility (Woodroof and Woodroof, 1927) of pollen produced by trees and its

Received for publication 22 Jan. 1997. Accepted for publication 15 Apr. 1997. The cost of publishing this paper was defrayed in part by the payment of page charges. Under postal regulations, this paper therefore must be hereby marked advertisement solely to indicate this fact. potential availability to regional orchards. Nevertheless, the detection of extensive self-pollination in many southeastern block-type orchards by Wood and Marquard (1992) suggests that pollinizer-related crop reductions are occurring. Block-type plantings, where a single cultivar typically occurs in sections 550 or more rows across, are common within the region and are becoming increasingly popular because of managerial advantages.

This report documents the occurrence of pollination-related crop reductions in blocktype orchards within the southeastern United States. It also provides insight into how pollinizer distance, spring temperatures, tree age/size, and the timing of the exposure of pistillate flowers to pollen influence pollination.

\section{Materials and Methods}

Experiment 1. Documentation of crop loss in block-type plantings due to lack of pollination. Pecan orchards are typically established in blocks composed of the main cultivars and one pollinizer (or rarely two). The pollinizer is often positioned on the orchard's perimeter or in rows $\geq 75 \mathrm{~m}$ from many main crop rows. 'Desirable' and 'Stuart' is one such cultivar pair commonly planted in the southeastern United States. Because 'Desirable' is protandrous (Type I) and 'Stuart' is protogynous (Type II), their floral maturity has been commonly assumed to be reciprocally complementary. Therefore, a large block-type or- chard of 'Desirable' and 'Stuart' was selected for study. A second orchard was also studied in which a small block of a single cultivar ('Pawnee') was planted next to a large orchard of supposedly complementary cultivars.

The first test orchard was located in the central zone of the Georgia Pecan Belt (near Albany, Ga.), and is near the primary U.S. production area. Trees were $\approx 15$ years old and were managed according to standard commercial practices (Crocker, 1995). The $\approx 150$-ha orchard was arranged in repeating blocks of 19 rows of 'Desirable' and four rows of 'Stuart'. Rows were N-S oriented and $15.4 \mathrm{~m}$ apart (50 feet) with $10.8 \mathrm{~m}$ (35 feet) between trees within the row. Orchard composition was almost exclusively these two cultivars, but with an occasional seedling tree (i.e., escaped rootstock) or "off-genotype" ("OG," another cultivar or an escaped rootstock). Other genotypes were fairly abundant within $1 \mathrm{~km}$ of the test orchard and many were present in the general vicinity.

Fruit-set of 'Desirable' trees, within the 'Desirable'/'Stuart' orchard, was atypically low in 1995. In the central zone of the block, the region most distant from the 'Stuart' pollinizer, fruit-set was evaluated on OG trees (classified based on morphological traits) proximate to other OG trees dispersing pollen during the receptivity period of 'Desirable'. These trees were selected from a low population randomly dispersed in the orchard's interior. Fruit-set was then assessed for five 'Desirable' trees at each "tree location," as trees radiated in all directions from these OG trees. Set was assessed by counting the number of fruit from 100 randomly selected fruiting clusters on terminal shoots from the mid exterior canopy of 'Desirable' trees, on the side facing the OG tree. This was repeated at five locations within the orchard. Data were then analyzed using PC-SAS by PROC G-CONTOUR (SAS, 1990) to derive a contour plot of fruitset.

The second test orchard was a pure 8-ha block of 9-year-old 'Pawnee' trees (protandrous) planted adjacent to a 40-ha orchard made up mostly of 85-year-old 'Stuart' (protogynous) and 'Schley' (protogynous), but also with randomly dispersed "seedling" or OG trees $(\approx 5 \%)$. The 'Pawnee' block was configured in $17 \times 18$ rows with trees spaced at $9 \times 9 \mathrm{~m}$. Putative pollinizers were in a contiguous U-shaped orchard immediately adjacent $(20 \mathrm{~m})$ to the 'Pawnee' block on the west and south sides and slightly set back (200 $\mathrm{m}$ ) on the north side. There was also 80 or more other genotypes growing within $0.5 \mathrm{~km}$. All trees in the 'Pawnee' block were evaluated for fruit-set in Oct. 1995 and 1996 by noting the number of nuts per tree. Fruit-set data were indexed to the cross-sectional area of the tree trunk and analyzed by PC-SAS for linear, quadratic, and cubic relationships. A contour map was then plotted using SAS G-CONTOUR (SAS, 1990).

Experiment 2. Fruit-set as a function of distance from pollinizer. The 15-year-old 'Desirable'/'Stuart' block was evaluated for the influence of pollinizer distance on fruit-set of 
the 'Desirable' "main crop." Fruit-set at ripening (October) was assessed, as described above, on four 'Desirable' trees in each row between the 'Stuart' pollinizer rows in both 1995 and 1996. The mean number of fruit per fruiting cluster on terminal shoots on the lower half of the southern side of the tree was then determined in each of five transects across the orchard to the next row of 'Stuart' pollinizers. Fruit-set per tree was then regressed against distance from the 'Stuart' pollinizers using PC-SAS regression analysis to determine linear and quadratic relationships.

Experiment 3. Influence of cultivar and tree age/size on relative flower maturation. Flowering patterns, as related to tree age or size, were evaluated for six protogynous ('Stuart', 'Moneymaker', 'Moore', 'Mahan', 'Schley', and 'Delmas') and two protandrous ('Desirable' and 'Dependable') cultivars 1ocated in adjacent orchards. Trees were commercially managed, irrigated, and well spaced. This ensured that the canopy was well exposed to sunlight and wind. Thus, sampled flowers were likely to be exposed to essentially the same air temperatures and radiant energy. Trees of these cultivars were segregated into two age classes: $<15$ years old or $>80$ years old. Because flower maturity varies by location within the tree, flowers were repeatedly selected from the lower exterior of the canopy ( 2 to $3 \mathrm{~m}$ aboveground for both age classes) and monitored daily for maturation of male and female flowers. Pistillate flowers were judged mature when pollen adhered to the stigmatic surface, whereas staminate flowers were mature when pollen could be released by gently shaking four randomly selected lower exterior limbs on the southern side of the tree. Experimental design was completely randomized, with two single-tree replicates of eight cultivars of two age classes $(<15$ and $>80$ years old) for a total of 32 trees.

Experiment 4. Influence of cultivar and temperature on relative maturation of flowers. The influence of temperature on flower maturation was assessed on five cultivars: three protandrous ('Desirable', 'Pawnee', and 'Caddo') and two protogynous ('Stuart' and 'Sumner'). Trees were $<15$ years old and under commercial management. The effect of temperature was estimated by exposing developing flowers to two temperature environments: 1) ambient and 2) elevated $\left(3\right.$ to $10^{\circ} \mathrm{C}$ above ambient; thus, the maximum ranged from $\approx 16$ to $37^{\circ} \mathrm{C}$ ). Elevated temperature was attained by enclosing a terminal shoot in a transparent 20 -L plastic bag tied around the 2year-old portions of the branch. Corners were removed to leave $10-\mathrm{cm}$-diameter holes for gas exchange and temperature moderation. Terminals were bagged $\approx 3$ weeks before flower maturity and temperature monitored using a thermocouple thermometer (Omega Engineering, Stamford, Conn.). Flowers were evaluated for date of maturation based on the above described criteria. The experimental design was a split-plot arranged in a completely random manner with two replicates of five cultivars (three protandrous and two protogynous) as the main plot and two temperature treat- ments (ambient and above ambient) per tree as the subplots ( $\mathrm{n}=10$ trees). Each temperature/ treatment subplot was replicated five times per tree per main plot.

Experiment 5. Duration of pistillate flower receptivity. The stigmatic surface of pistillate flowers was evaluated to assess the effective pollination period. Pistillate flower clusters of five 'Cheyenne' trees (replicates), possessing good flower crops, were covered with gaspermeable pollination bags (cellulose casings) $\approx 1$ to $3 \mathrm{~d}$ before receptivity. 'Desirable' pollen was dusted onto flowers a predetermined number of days after the initiation of receptivity. Receptivity was based on adherence of pollen to the stigmatic surface of flowers on adjacent flower clusters on the same shoot. Pollination treatments were such that 'Desirable' pollen was applied $1,2,4,6,8,10,15$, and $20 \mathrm{~d}$ after onset of pistillate flower receptivity. Pollen was lightly dusted onto flowers within the bag using a modified hypodermic syringe, with care being taken to avoid excessive application (Marquard, 1992). Twenty-five flower clusters per treatment on each of the three trees were ultimately pollinated ( $\mathrm{n}=75$ clusters). As controls, open-pollinated flower clusters were tagged and monitored for fruit drop throughout the summer. Developing nuts were evaluated 3 June, 20 June, 31 July, 1 Sept., and 20 Oct. to determine the percentage of fruit retention.

\section{Results}

Experiment 1. Documentation of crop loss in block-type plantings due to nonpollination. Trees located in the center of the 'Desirable' "main crop" blocks, far from 'Stuart' pollinizers, set few fruit unless located near an OG tree (Fig. 1). This trend held in both 1995 and 1996, but 1996 observations were subjective and are not presented. Fruit-set declined as distance from OG trees increased, and declined sharply by the third tree. This produced a plume-like pattern stretching from the southwest to the northeast across the orchard. This plume was aligned with the direction of the prevailing southwesterly winds during the pollination period. These data indicate that crop load was largely reduced by insufficient availability of 'Stuart' pollen at stigma receptivity.

Fruit-set in a second test orchard, an 8-ha 'Pawnee' block, declined in 1995 as the eastward distance from pollinizers increased [Fig. 2 , where set $(y)=a+b x^{2}+c x^{3} ; a=0.69, b=$ $\left.-4.29, c=1.46 \cdot 10^{-7} ; r^{2}=0.63\right]$. This gradient was consistent with prevailing southwesterly winds during the pistillate flower maturity window. Conversely, fruit-set increased in an easterly manner (or northeasterly) in 1996 (where $\mathrm{y}=\mathrm{a}+\mathrm{bx}^{2}+\mathrm{cx}^{3} ; \mathrm{a}=1.48 ; \mathrm{b}=0.00012$; $\left.\mathrm{c}=5.7 \cdot 10^{-7} ; r^{2}=0.85\right)$ when there was an atypical northeastern prevailing wind during the time of stigma receptivity of 'Pawnee'; thus, the pollen apparently came from pollinizers on the northern flank of the 'Pawnee' block. Trees with relatively high fruit-set tended to cluster within the 8-ha block, but fruit-set was not clearly related to proximity to OG trees or any obvious site-related condi-

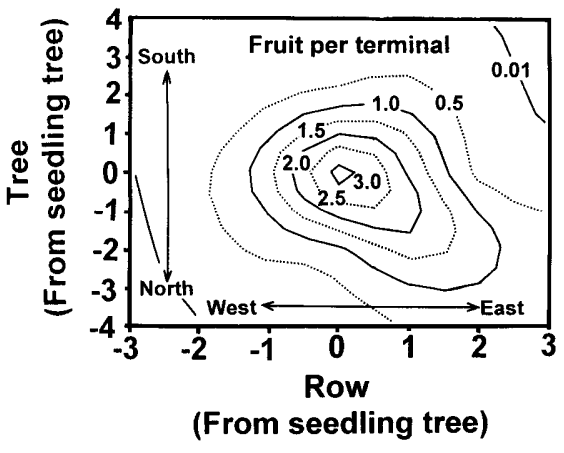

Fig. 1. Contour plot of fruit-set, or nuts per terminal, on 'Desirable' trees near seedling trees ("offgenotypes") in the region of a block-type 'Desirable'/'Stuart' orchard most distant from the 'Stuart' pollinizer. The plot is based on fruit-set of an average of five 'Desirable' trees per location as trees radiate from these "off-genotypes" within the 'Desirable' block. Fruit-set for the central area $(0,0)$ represents mean fruit-set of the five seedling trees.

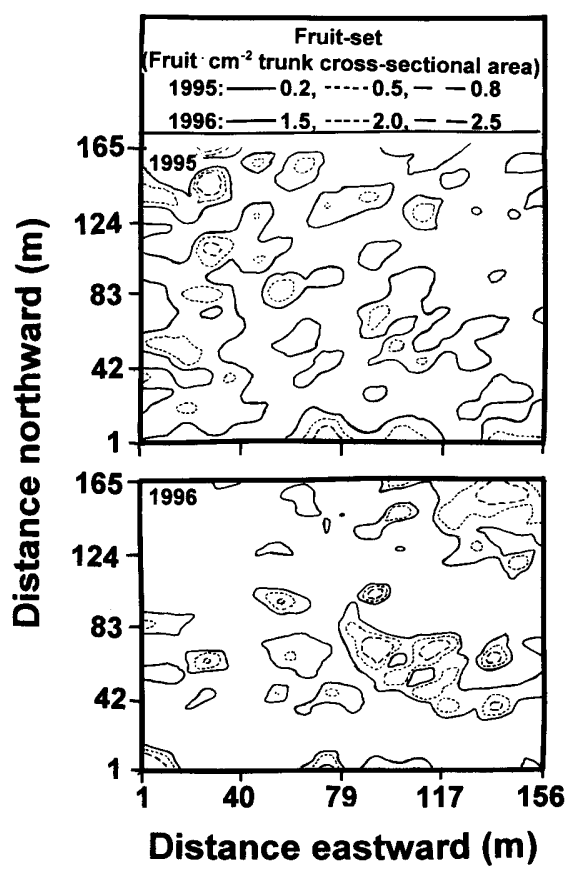

Fig. 2. Contour map, or distribution, of late season fruit-set within a block-type 'Pawnee' orchard, based upon distance from a large 'Stuart'/ 'Schley'/seedling orchard surrounding the 'Pawnee" block on the southern, western, and northern flanks. There was an eastward decline in fruit-set (y) in 1995, with $\mathrm{y}=\mathrm{a}+\mathrm{bx}^{2}+\mathrm{cx}^{3}(\mathrm{a}=$ $\left.0.69 ; \mathrm{b}=-4.29 ; \mathrm{c}=1.46 \cdot 10^{-7} ; r^{2}=0.63\right)$ and an eastward increase in set in 1996, with $y=a+b x^{2}$ $+\mathrm{cx}^{3}\left(\mathrm{a}=1.48 ; \mathrm{b}=0.00012 ; \mathrm{c}=5.7 \cdot 10^{-7} ; r^{2}=\right.$ $0.85)$.

tion. These wind-associated gradients in fruitset are evidence of insufficient pollen availability for the entire orchard.

Experiment 2. Fruit-set as a function of distance from pollinizer. Fruit-set of 'Desirable' in the 'Desirable'/'Stuart' block-type orchard declined sigmoidally as distance from the 'Stuart' pollinizer increased in both 1995 and 1996 (Fig. 3). Crop loads varied such that the 1995 crop was "light" and the 1996 crop was relatively heavy. There was a decline in fruit-set in both 1995 where set $(y)$ was $y=a+$ 
$\mathrm{bx}+\mathrm{cx}^{2}\left(\mathrm{a}=1.50 ; \mathrm{b}=-0.002 ; \mathrm{c}=-9.35 \cdot 10^{-5} ; r^{2}\right.$ $=0.96, \alpha \leq 0.001)$ and an eastward increase in set in 1996 where $\mathrm{y}=\mathrm{a}+\mathrm{bx}+\mathrm{cx}^{2}(\mathrm{a}=1.80 ; \mathrm{b}$ $\left.=-0.003 ; c=-1.18 \cdot 10^{-5} ; r^{2}=0.95, \alpha \leq 0.001\right)$. Fruit-set in 1995 averaged 1.2 fruit per terminal shoot on trees next to 'Stuart' pollinizers, but declined to $\approx 0.2$ (17\% fruit) at $\geq 75 \mathrm{~m}$. Although fruit-set was greater in 1996, trees farthest from 'Stuart' pollinizers still set onethird fewer fruit than those adjacent to the pollinizer. Fruit-set in both years declined with increasing distance from pollinizers; however, minimal set was at $160 \mathrm{~m}$ from the pollinizer in the "high crop" year but at $\geq 80 \mathrm{~m}$ in the "low crop" year. The decline in fruit-set with distance from pollinizer was most pronounced in the "light crop" year, where levels declined substantially beyond one row from the pollinizer. The maximum rate of change in fruit-set with pollinizer distance was at 49 $\mathrm{m}$ (row 3) in 1995 and at $78 \mathrm{~m}$ (row 5) in 1996.

Experiment 3. Influence of cultivar and tree age/size on relative flower maturation. Tree size/age altered maturation of both pistillate and staminate flowers (Fig. 4). Younger/ smaller trees exhibited a pollination window (the period of pollen dispersal) that was earlier and longer than that of older/larger trees of the same cultivar ( $\alpha \leq 0.05$, analysis of variance not shown). This was true for both protandrous and protogynous flowering types. All eight cultivars responded in this manner, although the degree of shift varied with genotype. Tree size/age also altered the receptivity period (the period during which pollen can adhere to the stigmatic surface); its duration was later and more prolonged in younger/smaller trees as compared to older/larger trees $(\alpha \leq 0.01)$. This delay in receptivity was $\approx 1$ to $3^{+} \mathrm{d}$, was true for all cultivars, and was independent of flowering type. The time between pollinating and receptivity windows was greatest for younger/ smaller trees and dichogamy tended to move toward incompleteness as trees aged or increased in size. These data indicate that the onset and duration of pistillate and staminate flower maturity windows vary with tree size/ age.

Experiment 4. Influence of cultivar and temperature on relative maturation offlowers. Spring temperatures altered the flowering patterns of all cultivars of both flowering types (Fig. 5). Exposing shoots to elevated temperatures advanced the maturity of both pistillate and staminate flowers by 2 to $5 \mathrm{~d}(\alpha \leq 0.01)$. The period between pollinating and receptivity windows under elevated temperatures was markedly increased for protandrous cultivars, but decreased for protogynous cultivars $(\alpha \leq$ 0.01 ). The mechanisms controlling flower maturation are therefore more sensitive to elevated temperatures in staminate than in pistillate flowers. Warmer conditions also reduced the duration of pollen dispersion and of pistillate flower receptivity $(\alpha \leq 0.01)$. Temperature-dependent advancement and retardation of flowering activity therefore alter pollinating and receptivity windows of both protandrous and protogynous cultivars.

Experiment 5. Duration of pistillate flower receptivity. Fruit-set of control pollinated flow- ers decreased ( 3 June, 20 June, 31 July, and 1 Sept.) as the time interval from initial receptivity of stigmatic surfaces to pollination increased (Fig. 6). The percentage of fruit-set, or retention, also declined for all treatments and the control as the season progressed. There was no further drop in fruit-set after 1 Sept. for any treatment. All fruit from flowers whose stigmatic surfaces received pollen more than four $\mathrm{d}$ after initial receptivity had aborted all fruit by 1 Sept. Although fruit from flowers whose stigmatic surfaces received pollen up to $20 \mathrm{~d}$ after initial receptivity did not abscise until at least 20 June, $\approx 7$ weeks after the normal pollination window, all such fruit had aborted by 31 July. Pollination of stigmatic surfaces of pistillate flowers within about one $\mathrm{d}$ of becoming receptive resulted in maximum fruit-set. These data show that pecan flowers can remain receptive for up to at least $4 \mathrm{~d}$ before exposure to pollen; however, pollination must occur as soon as possible after the stigmatic surface becomes receptive if high levels of fruit-set are to occur. Pollination one d after initial receptivity produced fruit-set levels essentially equal to those of open-pollinated flowers.

\section{Discussion}

Block-type plantings are common in the southeastern United States, a region where orchards are generally assumed to receive an abundance of pollen from nearby orchards, as well as from feral and yard trees (Woodroof and Woodroof, 1927). The present study has documented pollination deficiencies in orchards located in the heart of the Southeastern pecan belt and indicates that fruit-set problems can occur due to pollinizer distance, tree aging, and temperature-induced changes in flower maturity windows. The efficacy of pollinizers can therefore be highly variable. This variation indicates that orchards should contain more than one pollinizer if fruit-set problems are to be avoided throughout the life of the planting, and that pollinizers must be planted within a few rows of the main cultivar.

The observed pollination-related crop reductions support a previous conclusion that poor cross-pollination is occurring in many southeastern orchards (Wood and Marquard, 1992). This obviously does not occur in all orchards at all times. Altered flowering windows due to tree aging or to abnormal spring temperatures, as described in the present study, or to changes in relative humidity (Woodroof, 1930; Yates and Sparks, 1993) could easily trigger major pollination-related reductions. Additionally, Woodroof (1930) observed that pollen viability changes significantly $(0 \%$ to $82^{+} \%$ ) from year to year and from tree to tree, therefore potentially influencing fruit-set.

Greatly reduced fruit-set occurred when trees were more than $\approx 49 \mathrm{~m}$ from a pollinizer, and a $30 \%$ loss occurred only two rows from the pollinizer during a "light crop" year. This indicates that orchards of similar sized trees, spacings, and configuration should probably be established with main cultivars no

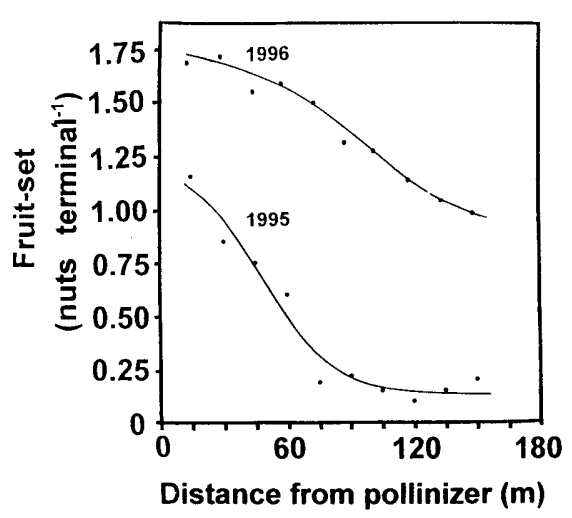

Fig. 3. Fruit-set in a large block-type orchard in 1995 and 1996 of 'Desirable' as a function of distance from the pollinizer ('Stuart'). Orchard configuration was repeating blocks of 19 rows of 'Desirable' and four rows of 'Stuart'. There was a decline in fruit-set $(y)$ in $1995\left[\mathrm{y}=\mathrm{a}+\mathrm{bx}+\mathrm{cx}^{2}\right.$ $\left(\mathrm{a}=1.50 ; \mathrm{b}=-0.002 ; \mathrm{c}=-9.3510^{-5} ; r^{2}=0.96\right.$, $\alpha \leq 0.001)]$ and an eastward increase in set in $1996\left[\mathrm{y}=\mathrm{a}+\mathrm{bx}+\mathrm{cx}^{2}(\mathrm{a}=1.80 ; \mathrm{b}=-0.003 ; \mathrm{c}=\right.$ $\left.\left.-1.18 \cdot 10^{-5} ; r^{2}=0.95, \alpha \leq 0.001\right)\right]$.

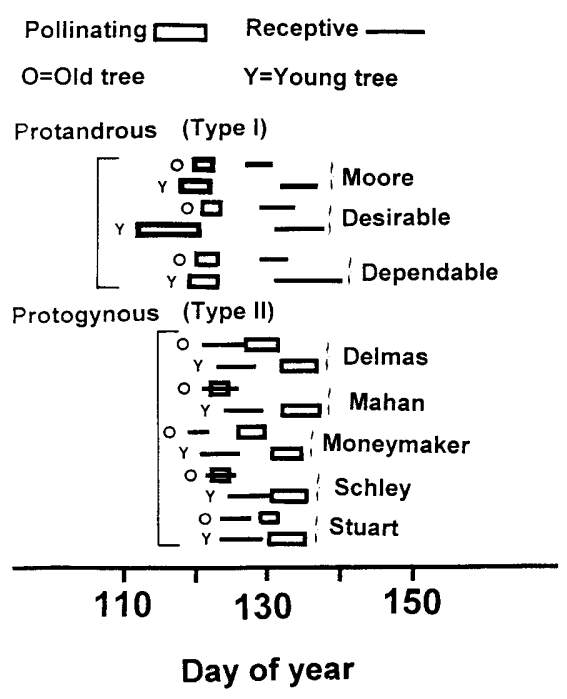

Fig. 4. Effects of cultivar and tree age/size on pollen shedding and pistil receptivity characteristics for protandrous and protogynous pecan cultivars.

more than one row from a pollinizer (i.e., main cultivars in double rows flanked by pollinizers). These data also indicate that if main cultivar rows are greater than or equal to about three to four rows (greater than or equal to $\approx 49 \mathrm{~m}$ ) from pollinizer cultivars, large crop reductions can occur in certain years. Even in relatively good years, main cultivars (rows greater than or equal five to six rows from pollinizers) are likely to exhibit substantial crop reductions. Thus, the main cultivar section of block-type orchards should probably be less than or equal to $\approx 10$ to 12 rows, and two to three rows will probably give much better fruit set than 10 to 12 row blocks. Even then, cross-pollination-related crop reductions will probably occur, because observations by Marquard (1988) and Wood (personal observations) on 'Western Schley' and 'Wichita' block-type planting in the southwestern United States indicate that main cul- 


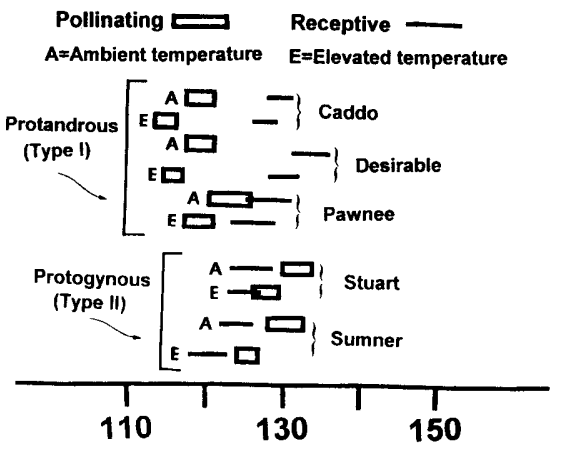

Day of year

Fig. 5. Effect of cultivar and elevated temperatures before flower maturity on pollen and pistil receptivity characteristics for protandrous and protogynous pecan cultivars.

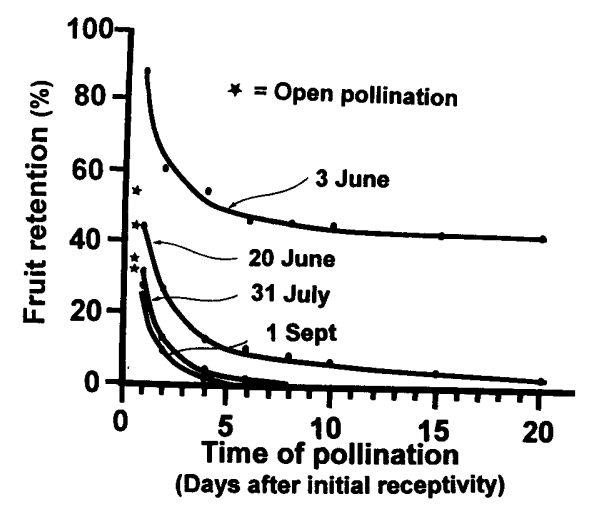

Fig. 6. Influence of the time of pollination on fruitset of 'Cheyenne' pecan. Percentage fruit retention (y) is described by the equation: $y=a+b /$ $x$, where $x=$ time interval between initial receptivity and pollination. For June $3, \mathrm{a}=42.6, \mathrm{~b}=$ $44.3, r^{2}=0.85, \alpha \leq 0.001$; for June $20, a=4.6$, $\mathrm{b}=39.7, r^{2}=0.94, \alpha \leq 0.001$; for July $31, \mathrm{a}=-$ $3.2, \mathrm{~b}=26.9, r^{2}=0.96$; for Sept. $1, \mathrm{a}=-2.7, \mathrm{~b}=$ $23.1, r^{2}=0.96, \alpha \leq 0.001$.

tivars more than two rows from the pollinizer exhibited reduced fruit-set and lower percentage kernel (the latter due to increased self-pollination). Because of the interactive influences of distance, tree size, and pollinizer density, the optimum distance or number of main cultivar rows for pecan orchards in general cannot be derived from these data.

Although pecan flowers abort within a few weeks after pollination when excessive pollen lands on the stigmatic surface, the 'Desirable'/ 'Stuart' and 'Pawnee' trees used in the present study gave no indication that this occurs at significant levels under orchard conditions; however, this has been reported for certain walnut cultivars (McGranahan, 1994). Conversely, observations by the author indicate that alternating rows of complementary pollinizers result in maximum fruit-set and yields.
This study also indicates that pecan exhibits reduced fruit-set if pistillate flowers fail to receive pollen within $\approx 1 \mathrm{~d}$ after becoming receptive; if no pollination occurs within $\geq 4 \mathrm{~d}$, then there is likely to be little or no fruit-set. The cause of these fruit-drops remains undetermined, although visual observations of the stigmatic surface revealed they had become swollen and distorted and appeared to lose much of their moist appearance 3 to $4 \mathrm{~d}$ after initial receptivity. Because pollen grains on the stigmatic surface require rehydration before germination and germ tube penetrate of the stigmatic surface (Wetzstein and Sparks, 1989), insufficient moisture on the aged stigmatic surface may prevent germination and fertilization and therefore fruit-set.

Fruit developing following pollination in early May ultimately dropped in late July, indicating that either fruit can develop for several weeks after the normal pollination period without being fertilized or that something associated with delayed fertilization eventually causes fruit to abort. Visual inspection revealed that aborting fruit were smaller than those retained.

The apparent need for pollination soon after stigma receptivity illustrates the vulnerability of orchard systems to shifts in flower maturity windows, especially in orchards composed of two cultivars with a protogynous primary cultivar. Thus, reliance on a single pollen source is risky, for pollination may occur too late. For insurance, orchards should probably contain at least two nearby pollinizers. Woodroof (1924) came to a similar conclusion, but the idea has been largely abandoned in recent years due to the assumed abundance of pollen from pollinizers nearby. Pollinizers could be segregated in rows, or cultivars possessing nut shapes nearly identical to that of the main cultivar could be positioned within rows of the main cultivar. For example, 'Stuart'/ 'Cape Fear' or 'Desirable'/'Kiowa' combinations would provide enhanced pollination without a reduction in price due to mixed nuts. A comprehensive listing of flower maturity windows recently developed for southeastern U.S. conditions by Wood et al. (1997) can be used to facilitate pollinizer selection.

Extrapolation of these studies suggests that southeastern orchards should be designed such that the main cultivar is pollinated by two or more cultivars possessing good reciprocal complementarity under normal conditions. Many patterns of cultivar placement within orchards are available, based upon relative cultivar value, tree removal strategy, and a variety of cultural or pest management strategies. Whatever the design selected, these data indicate that main cultivar trees should be as close to a pollinizer as is practical and that blocks greater than two to three rows will probably exhibit substantial pollination-related crop reductions.

\section{Literature Cited}

Adriance, G.W. 1930. Dichogamy in the pecan. Proc. Amer. Soc. Hort. Sci. 27:435-439.

Buban. T. 1996. Flower development and formation of sexual organs, p. 3-54. In: J. Nyeki and M. Soltesz (eds.). Floral biology of temperate zone fruit trees and small fruits. Akademiai Kiado, Budapest.

Crocker, T.F. 1995. Commercial pecan production in Georgia. Univ. of Georgia Coop. Ext. Bul. 609.

Grauke, L.J. and T.E. Thompson. 1996. Pecans and hickories, p. 185-239. In: J. Janick and J. Moore (eds.). Fruit Breeding, vol. III. Wiley, New York.

Marquard, R.D. 1988. Outcrossing rates in pecan and the potential for increased yields. J. Amer. Soc. Hort. Sci. 113:84-88.

Marquard, R.D. 1992. Fruit-set of pecan requires a low percentage of live pollen in controlled pollination. HortScience 27:473.

McGranahan, G.H., D.G. Voyiatzis, P.B. Catlin, and V.S. Polito. 1994. High pollen loads can cause pistillate flower abscission in walnut. $\mathbf{J}$. Amer. Soc. Hort. Sci. 119:505-509.

Romberg, L.D. and C.L. Smith. 1946. Effects of cross-pollination, self-pollination and sib-pollination on the dropping, the volume and the kernel development of pecan nuts and on the vigor of the seedling. Proc. Amer. Soc. Hort. Sci. 47:130-133.

SAS Institute. 1990. SAS/Graph Software: Reference, version 6, vol. 2. SAS Inst., Cary, N.C.

Smith, C.L. and L.D. Romberg. 1941. Pollen adherence as a criterion of the beginning of stigma receptivity in the pecan. Proc. Texas Pecan Growers Assn. 21:38-45.

Soltesz, M. 1996. Flowering, p. 80-131. In: Nyeki and $M$. Soltesz (eds.). Floral biology of temperate zone fruit trees and small fruits. Akademiai Kiado, Budapest.

Sparks, D. and G.D. Madden. 1985. Pistillate flower and fruit abortion in pecan as a function of cultivar, time, and pollination. J. Amer. Soc. Hort. Sci. 110:219-223.

Wetzstein, H.Y. and D. Sparks. 1989. Stigma-pollen interactions in pecan. J. Amer. Soc. Hort. Sci. 114:355-359.

Wood, B.W. and R.D. Marquard. 1992. Estimates of self-pollination in pecan orchards in the southeastern United States. HortScience 27:406-408.

Wood, B.W., M.W.Smith, R.E. Worley, P.C. Anderson, T.E. Thompson, and L.J. Grauke. 1997. Reproductive and vegetative characteristics of pecan cultivars. HortScience 32:1028-1033.

Woodroof, J.G. 1924. The development of pecan buds and quantitative production of pollen. Georgia Agr. Expt. Sta. Bul. 144:134-161.

Woodroof, J.G. 1930. Studies of the staminate inflorescence and pollen of Hicoria pecan. J. Agr. Res. 40:1059-1104.

Woodroof, J.G. and N.C. Woodroof. 1927. Distance pecan pollen is carried by wind for practical purposes. Georgia-Florida Pecan Growers Assn. 21:43-45.

Worley, R.E., S.K. Dove, B.G. Mullinix, Jr., and M. Smith. 1992. Long-term dichogamy of 80 pecan cultivars. Scientia Hort. 49:93-101.

Yates, I.E. and D. Sparks. 1993. Environmental regulation of anther dehiscence and pollen germination in pecan. J. Amer. Soc. Hort. Sci. 118:699-706. 